\title{
The green sturgeon and its environment: introduction
}

\author{
A. Peter Klimley • Peter J. Allen • \\ Joshua A. Israel · John T. Kelly
}

Received: 10 August 2006/ Accepted: 26 September 2006

(C) Springer Science+Business Media B.V. 2006

The green sturgeon, Acipenser medirostris, is one of two acipenserid fishes native to the temperate waters of the Pacific coast of North America. Originally, three species of sturgeon were described from this region, and this one named "medirostris" or "middle snout" based on the length of its rostrum relative to the other purported species (Ayers 1854), both of which were later determined to be white sturgeon, Acipenser transmontanus (Moyle 2002). The green sturgeon is similar in appearance to the congeneric white sturgeon, with which it cooccurs, except that its barbels are usually closer to the mouth than to the tip of the snout. Green sturgeon are heavily armored, possessing one dorsal, two lateral and two bottom rows of scutes or bony plates (Moyle 2002). In addition, there are often one or two large scutes behind the dorsal fin, as well as one behind the anal fin, which are both lacking in the white sturgeon. The common name of the species is apt due its

A. P. Klimley $(\bowtie) \cdot$ P. J. Allen · J. T. Kelly

Department of Wildlife, Fish \& Conservation

Biology, University of California, One Shields

Avenue, Davis, CA 95616, USA

e-mail: apklimley@ucdavis.edu

\section{J. A. Israel}

Department of Animal Science, University of California, One Shields Avenue, Davis, CA 95616, USA distinctly olive-green body color, with olivaceous stripes usually present on its sides and ventral surface.

Green sturgeon are currently thought to be comprised of two genetically distinct breeding populations (Israel et al. 2004): a northern distinct population segment (DPS) consisting of fish that spawn in the Rogue River, Oregon (Erickson et al. 2002), and the Klamath River, California (Van Eenennaam et al. 2001), and a southern DPS that spawns in the Sacramento River, California. Increasingly, many fish species are being recognized as consisting of multiple, genetically distinct stocks. In many cases, these stocks are managed separately because of distinctive phenotypic, physiological, and behavioral characteristics representative of the unique adaptations each stock has to the environmental conditions in a particular habitat (Waples 1995). Although little is known about what distinguishes these green sturgeon populations biologically, several unique physical characteristics differentiate the river systems in which they occur. Tidal flows in an expansive estuary, voluminous flows, long river length, and multiple tributaries in an extensive watershed distinguish the Sacramento River from the Rogue and Klamath Rivers with their small estuaries, relatively short length, and smaller watersheds. Based on the best information available to the National Marine Fisheries Service (Adams et al. in press), the southern DPS was 
listed as "threatened" on April 8, 2006 under the U.S. Endangered Species Act.

The amount of rainfall in the watersheds on the western coast of North America that are inhabited by green sturgeon varies greatly between years, and this affects what reaches of these rivers sturgeon can utilize on successive years. Furthermore, the timing of the rainfall influences the environmental conditions under which the eggs and juveniles develop within the river through changes in flow timing and volume, and the resulting differences in temperatures and dissolved oxygen concentration. Green sturgeon appear to be adapted to this level of natural environmental variability. Individuals of the species migrate extensive geographic distances over the continental shelf (Moyle 2002; Erickson and Hightower in press; Lindley, personal communication), always returning to their natal rivers to spawn, although they would appear to be capable of occupying other rivers that may be more favorable depending on the rainfall in a given year. Once spawning has occurred, the large size of the eggs, demersal behavior of the larvae (Kynard et al. 2005), rapid growth of the young (Deng et al. 2002), and early seawater tolerance (Allen and Cech 2007) appear to be adaptations for life in short, coastal river systems (Artyukhin and Andronov 1990).

Green sturgeon possess a reproductive strategy intermediate to the two conventionally opposing "r-selected" and "K-selected" life history types (Pianka 1970). A classical r-selected species grows rapidly, reaches maturity early, reproduces often, and produces many eggs, but is short lived-adaptations that promote success in variable environments. The Pacific sardine, Sardinops sagax, is a good example of a coastal pelagic species with $\mathrm{r}$ selected traits, growing to maturity within 2 years, reproducing multiple times each year, producing up to 2 million eggs per year, but typically living for less than 8 years. In contrast, K-selected species grow slowly, reach maturity at an advanced age, and have few young, but are long lived-adaptations that result in greater success in stable environments where competition is greater among species. For example, the scalloped hammerhead, Sphyrna lewini, is an archetypal K-selected species. It takes up to 15 years to reach maturity, gives birth to only $12-40$ pups every other year, but can live up to 35 years (Klimley 1999).

Aspects of the reproductive biology of the green sturgeon resemble those of K-selected species inhabiting stable environments. Females spawn at an advanced age and infrequently. Adult females captured during their spawning migration in the Klamath River ranged from 16 to 40 years old (Van Eenennaam et al. 2006). Based on their taxonomic affinity, spawning is thought to occur every 5 years (Tracy 1990), though individuals tagged with coded ultrasonic transmitters have been found to return after 2-4 years to upstream pools in the Rogue River, Oregon, where they were believed to be spawning (Erickson and Webb in press). Assuming an age at first spawning of 16 years, and using conservative estimates of both life-span and average spawning periodicity, 50 years (Nakamoto 1995) and 4 years, respectively, the oldest females of the species might be expected to spawn only eight times within their lifetime. Despite these K-selected traits, the green sturgeon also resembles an r-selected species adapted to variable environments, in that females produce many eggs per spawn. Their fecundity increases with the size of the mature female, ranging from 59,000 to 242,000 eggs (Van Eenennaam et al. 2006). Compared with other sturgeon species, though, the number of eggs produced per spawning event relative to body weight is quite low due to the large egg size, which is second in size only to Chinese sturgeon, Acipenser sinensis (Van Eenennaam et al. 2006). Such a life history strategy suggests that green sturgeon have evolved to tolerate short-term stochasticity in their environment resulting from annual variability in weather and river conditions, yet the species may be highly sensitive to larger scale changes such as habitat loss or permanent alteration of flow regime. In its combination of life history characteristics, the green sturgeon would be classified as a "periodic strategist" in the more diverse classifications of Winemiller and Rose (1992) and King and McFarlane (2003). Given the current conservation interest in this species, basic biological studies of the kind presented herein are of timely importance.

This special issue of Environmental Biology of Fishes is largely comprised of articles with results 
Fig. 1 Evgenii Artyukhin (left) shown in 1998 at a hatchery in Astrakhan in the Volga Delta where he was artificially spawning beluga sturgeon

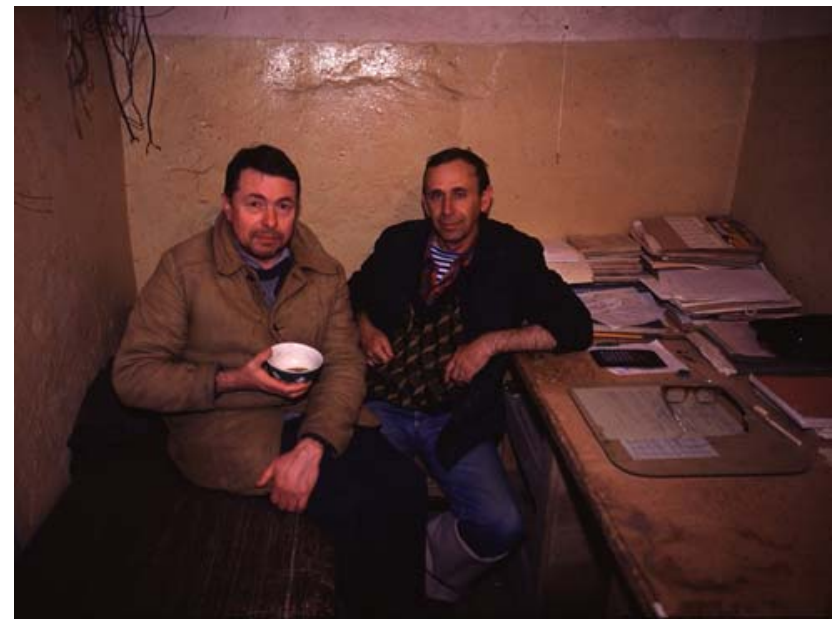

presented at a symposium on the biology of the green sturgeon held at the 39th Annual Meeting of the California-Nevada chapter of the American Fisheries Society in March 2005. Funding for this symposium was provided by CalFed contract ERP-02D-P57. We have organized the articles under four subjects: physiology, movements, population biology, and distribution. The articles present new observations that provide a greater understanding of the relationship between this species and its environment.

We appreciate the continued assistance of Lynn Bouvier, Assistant to the Editor of Environmental Biology of Fishes, and Suzanne Mekking, Publishing Editor for Aquatic Sciences at Springer, in producing this Special Issue. Also critical was David Noakes, the Editor-in-Chief of the journal, who showed keen interest in publishing the materials of the green sturgeon symposium as a dedicated issue of the journal.

We dedicate this volume to Evgenyi Artyukhin of the Central Laboratory of Fish Reproduction in Saint Petersburg, Russia (Fig. 1). Evgenyi gave a well-organized and polished presentation about the biology of the Sakhalin sturgeon, Acipenser mikadoi, which inhabits the Tumnin River situated on the eastern coast of Russia. The relationship of this species to green sturgeon, whether as subspecies or congener, is still uncertain, based on conflicting morphometric, cytogenetic, and genetic evidence (Artyukhin and Vecsei in press). We remember Evgenyi smiling at our table during the banquet, and were stunned when we heard that he died of cancer a month after the meeting. Paul Vecsei bore the daunting task of converting Evgenyi's notes and presentation into an article for the volume. As Paul indicated in correspondence, some of the information that we would have hoped be in the article was unfortunately lost with him upon his untimely death in Russia.

\section{References}

Adams PB, Grimes C, Hightower J, Lindley ST, Moser ML, Parsley MJ (in press) Population status of North American green sturgeon, Acipenser medirostris. Environ Biol Fish

Allen PJ, Cech JJ Jr (2007) Age/size effects on juvenile green sturgeon, Acipenser medirostris, oxygen consumption, growth, and osmoregulation in saline environment. Environ Biol Fish (in press)

Artyukhin N, Andronov AE (1990) A morphobiological study of the green sturgeon Acipenser medirostris (Chondrostei, Acipenseridae), from the Tumnin (Datta) River and some aspects of the ecology and zoogeography of Acipenseridae. J Ichthyol 30:11-21

Artyuhkhin EN, Vecsei P (in press) Morphology and ecology of Pacific sturgeons. Environ Biol Fish

Ayers WO (1854) Descriptions of new species of fish from San Francisco Bay. Proc Calif Acad Nat Sci 1:3-22

Deng X, Van Eenennaam JP, Doroshov SI (2002) Comparison of early life stages and growth of green and white sturgeon. Am Fish Soc Symp 28:237-248

Erickson DL, Hightower JE (in press) Oceanic distribution and behavior of green sturgeon. In: Munro J, Hatin D, McKown K, Hightower J, Sulak K, Kahnle A, Caron F (eds) Proceedings of the symposium on anadomous sturgeon: status and trends, anthropogenic impacts and essential habitats. Am Fish Soc

Erickson DL, North JA, Hightower JE, Weber J, Lauck L (2002) Movement and habitat use of green sturgeon, 
Acipenser medirostris, in the Rogue River, Oregon, USA. J Appl Ichthyol 18:565-569

Erickson DL, Webb MAH (in press) Spawning periodicity, spawning migration, and size at maturity of green sturgeon, Acipenser medirostris, in the Rogue River, Oregon. Environ Biol Fish

Israel JA, Cordes JF, Blumberg MA, May B (2004) Geographic patterns of genetic differentiation among collections of green sturgeon. N Am J Fish Manag 24:922-931

King JR, McFarlane GA (2003) Marine fish life history strategies: applications to fishery management. Fish Manag Ecol 10:249-264

Klimley AP (1999) Sharks beware. Am Sci 87:488-491

Kynard B, Parker E, Parker T (2005) Behavior of early life intervals of Klamath River green sturgeon, Acipenser medirostris, with a note on body color. Environ Biol Fish 72:85-97

Moyle PB (2002) Inland fishes of California. University of California Press, Berkeley

Nakamoto RJ, Kisanuki TT, Goldsmith GH (1995) Age and growth of Klamath River green sturgeon
(Acipenser medirostris). U.S. Fish and Wildlife Service Report 93-FP-13. Yreka, CA

Pianka ER (1970) On r- and K-selection. Am Nat 104:592-597

Tracy C (1990) Memorandum. Green sturgeon meeting and comments. Department of Fisheries, State of Washington, $10 \mathrm{pp}$

Van Eenennaamm JP, Linares-Casenave J, Doroshov SI (2006) Reproductive conditions of the Klamath River green sturgeon (Acipenser medirostris). Trans Am Fish Soc 135:151-163

Van Eenennaam JP, Webb MAH, Deng X, Doroshov SI, Mayfield RB, Cech JJ Jr, Hillemeier DC, Willson TE (2001) Artificial spawning and larval rearing of Klamath River green sturgeon. Trans Am Fish Soc 130:159-165

Waples RS (1995) Evolutionarily significant units and the conservation of biological diversity under the Endangered Species Act. Cons Biol Divers 17:8-27

Winemiller KO, Rose KA (1992) Patterns of life-history diversification in North American fishes: implications for population regulation. Can $\mathrm{J}$ Fish Aquat Sci 49:2196-2218 